\title{
Review
}

[Journal of Environmental Chemistry Vol.12, No.3, pp.563-569, 2002]

\section{Comparison of Analytical Methods for PCDD/Fs and Coplanar PCBs between Japan and Korea}

\author{
Jae-Won CHOI and Masatoshi MORITA \\ National Institute for Environmental Studies \\ (16-2 Onogawa, Tsukuba, Ibaraki 305-8506)
}

[Received June 12, 2002]

\begin{abstract}
Summary
The standard analytical methods for polychlorinated dibenzo-p-dioxins (PCDDs), polychlorinated dibenzofurans (PCDFs) and coplanar polychlorinated biphenyls (Co-PCBs) in flue gas used in Japan (JIS K 0311) and Korea (The Korean Standard Method for Air Pollution, KS method) were compared. No significant differences from sampling to the identification and quantification steps were found. However, adoption of Co-PCBs and the TEF model should be unified in JIS K 0311 and the KS method in order to compare the toxic equivalents (TEQs). We believe that this study will contribute to the standardization of an international method for dioxin analysis.
\end{abstract}

Key words: PCDD/F, Co-PCB, JIS K 0311, KS method, TEF, Analysis

\section{INTRODUCTION}

Dioxins have many congeners/homologues and their levels in the environment are often reported as ppt levels.

Since sampling and sample preparation, extraction, clean up and instrumental measurements are difficult and time consuming, well-trained personnel with many skills are needed. Various methods for determining dioxins have been developed, their use depending on the target sample and the conditions of the country.

In Japan, several analytical methods including JIS $\mathrm{K} 0311$ for emission gas and JIS K 0312 for wastewater, and manuals for ambient air, soils, foodstuff and wildlife etc. have been published. On the other hand, an analytical method for particulate and gaseous dioxins in the flue gas from municipal solid waste incinerators (MSWI) has been presented as a standard method in Korea (The Korean Standard Method for Air Pollution, KS method). Since both Japan and Korea have similar industries and policies for waste treatment, we assumed that both countries would have the same crite- ria for estimating dioxins. However, there have been no comparisons of analytical methods and the data obtained in Japan and Korea.

The aim of this review was to compare the standard analytical methods for dioxins used in Japan and Korea and discuss improvement of the methods. Details of the sampling, clean up, instrumental analysis and toxic equivalency factors (TEFs) were compared.

\section{SELECTED ANALYTICAL METHODS}

The standard analytical methods for dioxins in emission gas from MSWI, i.e., JIS K 0311 and the KS method, were chosen for comparison. The comparisons and discussion are divided into sampling, clean up, and identification and quantification sections.

\section{Sampling}

Sampling methods for flue gas are summarized in Table 1. A basic difference between the JIS K 0311 and KS methods was found with respect to the range of target compounds. Coplanar PCBs are counted as dioxin-like compounds in JIS K 0311, but only PCDDs 
and PCDFs are designated as dioxins in the $\mathrm{KS}$ method. The sampling equipments in JIS K 0311 and the KS method are based on sampling trains containing several impingers connected to a cooled adsorbent such as XAD-2 (Fig. 1 and Fig. 2). Particles are supposed to be collected in the impingers while the vapor phases are collected in the cooled adsorbent column. JIS K 0311 recommends two steps of the adsorbent column depending on the conditions. The details of the sampling method and the sample volume are similar each other in JIS K 0311 and the KS method. The labeled internal standards are spiked prior to sampling. For standards as sampling spikes, JIS K 0311 uses more than one appropriate congener, but the $\mathrm{KS}$ method designates ${ }^{37} \mathrm{Cl}_{4}-2,3,7,8$-TCDD as the sampling standard.

\section{Clean Up}

Sample preparations in JIS K 0311 and the KS method are essentially separated into the following steps; i.e., measurement of the sample volume, spiking labeled standards as clean up spike, and clean up procedures. The comparison of the two methods is shown in Table 2. A major difference lies in the spike procedure of the internal standards. The JIS method considers the volume of the spike and recommends that the internal standards should be added prior to the extraction procedure. However in the KS method, fifteen labeled compounds are added after the extraction procedure to check and correct the efficiency of the clean up process while extraction efficiency is evaluated separately by ${ }^{37} \mathrm{Cl}$-labeled TCDD. The required recoveries of JIS K 0311 and the KS method are in the same range of $50 \sim 120 \%$. The sample clean up procedures consisting of sulfuric acid treatment, silica gel chromatography, alumina chromatography and activated carbon chromatography, are adopted. The outlines of clean up in both methods are almost same. JIS K 0311

Table 1 Comparison of sampling methods between JIS K 0311 and KS method

\begin{tabular}{|c|c|c|}
\hline Country & Japan & Korea \\
\hline Manual & JIS K 0311 & KS method \\
\hline Target Compounds & PCDD/Fs, Co-PCBs & PCDD/Fs \\
\hline Sampler & sampling trains with impingers and adsorbent & sampling trains with impingers and adsorbent \\
\hline Vacuum Flow & constant flow & constant flow \\
\hline Filtration Media & cylinder type, maintain below $120^{\circ} \mathrm{C}$ & cylinder type, maintain below $120^{\circ} \mathrm{C}$ \\
\hline Composition of Sampler & water-water-empty-diethylene glycol-empty-water & water-water-empty-diethylene glycol-empty-water \\
\hline Adsorbent & styrene dibenyl benzene polymer & XAD2 or same grade materials \\
\hline $\begin{array}{l}\text { Sampling Method, } \\
\text { Volume }\end{array}$ & $\begin{array}{l}\text { depending on the conditions } \\
\text { flow rate should be within }-5 \sim 10 \% \\
\text { between the nodule and the measuring point }\end{array}$ & $\begin{array}{l}\text { above } 3 \mathrm{Nm}^{3} \text { during } 4 \mathrm{hr} \text { average } \\
\text { flow rate should be within }-5 \sim 10 \% \\
\text { between the nodule and the measuring point }\end{array}$ \\
\hline Sampling Spike & $\begin{array}{l}\text { more than one appropriate congener should be spiked } \\
\text { example) }{ }^{13} \mathrm{C}_{12}-2378-\mathrm{TeCDF} \\
{ }^{13} \mathrm{C}_{12}-1234789-\mathrm{HpCDF} \\
{ }^{13} \mathrm{C}_{12}-23^{\prime} 45^{\prime}-\mathrm{TeCB}(\# 70) \\
\text { spiking volume, } 1-20 \mathrm{ng} \\
\text { recovery range, } 70-130 \% \\
\text { possible to omit the spiking with constant quality }\end{array}$ & $\begin{array}{l}{ }^{37} \mathrm{Cl}_{4}-2378-\mathrm{TCDD} \\
\text { spiking volume, } 4-10 \mathrm{ng}\end{array}$ \\
\hline Others & travel blank & - \\
\hline
\end{tabular}

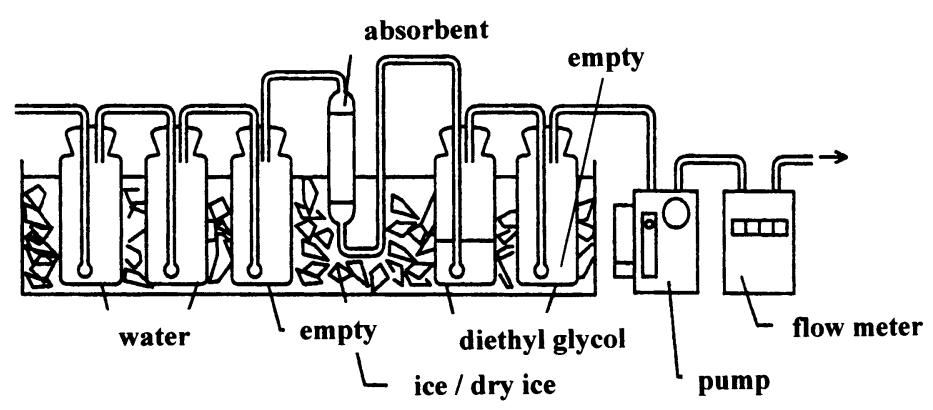

Fig. 1 Sampling equipment suggested in JIS K 0311 
recommends the use of multi-layered silica gel column chromatography instead of sulfuric acid treatment and silica gel column chromatography. If necessary, HPLC column chromatography or activated carbon column chromatography can be used in JIS K 0311 after alumina column chromatography. The measurement of coplanar PCBs and the methods of separating the $\mathrm{Co}^{-}$ $\mathrm{PCB}$ from the PCDD/F fraction after silica gel column chromatography are illustrated (Fig. 3). Prior to GC/MS injection, both JIS K 0311 and the KS method designate that an appropriate labeled internal standard solution (syringe spikes) should be added to the cleanedup fraction. The whole clean up procedures are shown in Fig. 3 for JIS K 0311 and Fig. 4 for the KS method.

\section{Identification and Quantification}

The details of identification and quantification of dioxins in both methods are similar each other. The procedures are performed with a capillary column high resolution gas chromatograph-high resolution mass spectrometer (HRGC/HRMS). One or two $\mu \ell$ of the cleaned up sample solution is injected into the GC/MS using on-column or splitless mode. The details of the capillary fused silica column are described in JIS $\mathrm{K}$ 0311. The KS method designates that a polar capillary column or a column warranted for the elution orders should be used for the GC/MS analysis. Adjustment or mass calibration should be carried out until all performance criteria for the measurements are completely met. The required resolution of the mass spectrometer

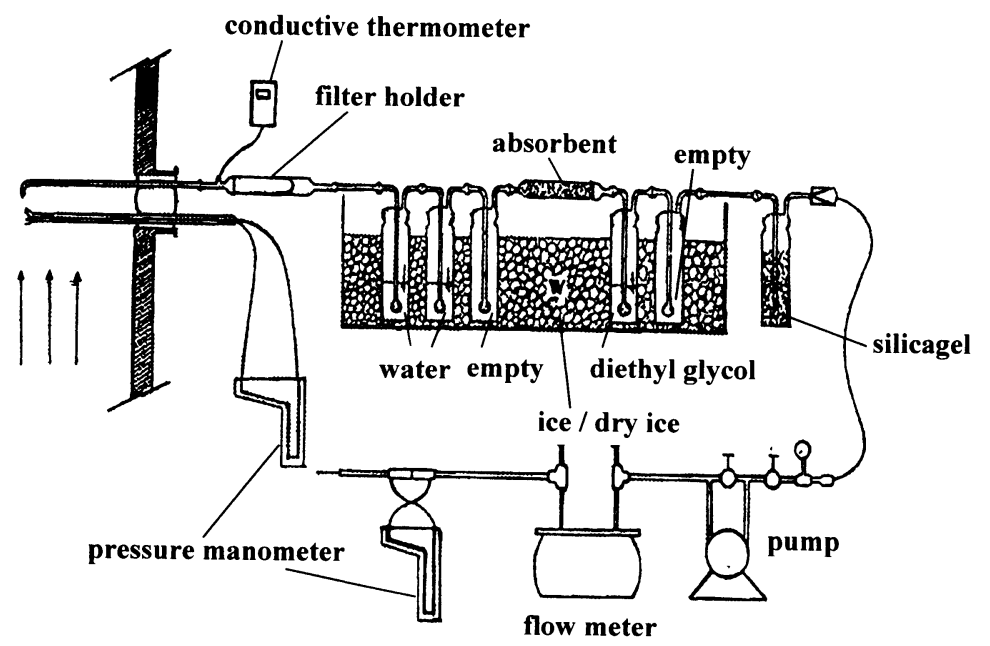

Fig. 2 Sampling equipment suggested in KS method

Table 2 Comparison of clean up methods between JIS K 0311 and KS method

\begin{tabular}{|c|c|c|}
\hline Country & Japan & Korea \\
\hline Manual & $\begin{array}{r}\text { JIS K } 0311 \\
\end{array}$ & KS method \\
\hline $\begin{array}{l}\text { Spiking of } \\
\text { Internal Standards }\end{array}$ & $\begin{array}{l}\text { PCDD/Fs 9 } 13 \text { congeners, } \\
\text { Co-PCBs } 7 \sim 8 \text { congeners }\end{array}$ & PCDD/Fs 15 congeners \\
\hline (Clean up spike) & $\begin{array}{l}\text { filter paper, adsorbent matrials, rinsing water } \\
\text { spike prior to extraction }\end{array}$ & $\begin{array}{l}\text { filter paper, adsorbent matrials, rinsing water } \\
\text { spike after extraction }\end{array}$ \\
\hline Spiking Volume & $\begin{array}{l}4 \sim 7 \mathrm{CDD} / \mathrm{F} 0.4 \sim 2 \mathrm{ng}, 8 \mathrm{CDD} / \mathrm{F} 0.8 \sim 4 \mathrm{ng}, \\
\text { Co-PCB } 0.4 \sim 2 \mathrm{ng} \\
\text { addtional spike is possible }\end{array}$ & no designation \\
\hline Recovery & $50 \sim 120 \%$ & $50 \sim 120 \%$ \\
\hline $\begin{array}{l}\text { Preparations } \\
\text { (Clean up) }\end{array}$ & $\begin{array}{l}\text { sulfuric acid treatment } \\
\text { silica gel column chromatography } \\
\text { or multi-layered silica gel column chromatography } \\
\text { separation PCDD/F to co-PCB } \\
\text { alumina column chromatography } \\
\text { HPLC column chromatography } \\
\text { active carbon column chromatography, if necessary }\end{array}$ & $\begin{array}{l}\text { sulfuric acid treatment } \\
\text { silica gel column chromatography }\end{array}$ \\
\hline
\end{tabular}




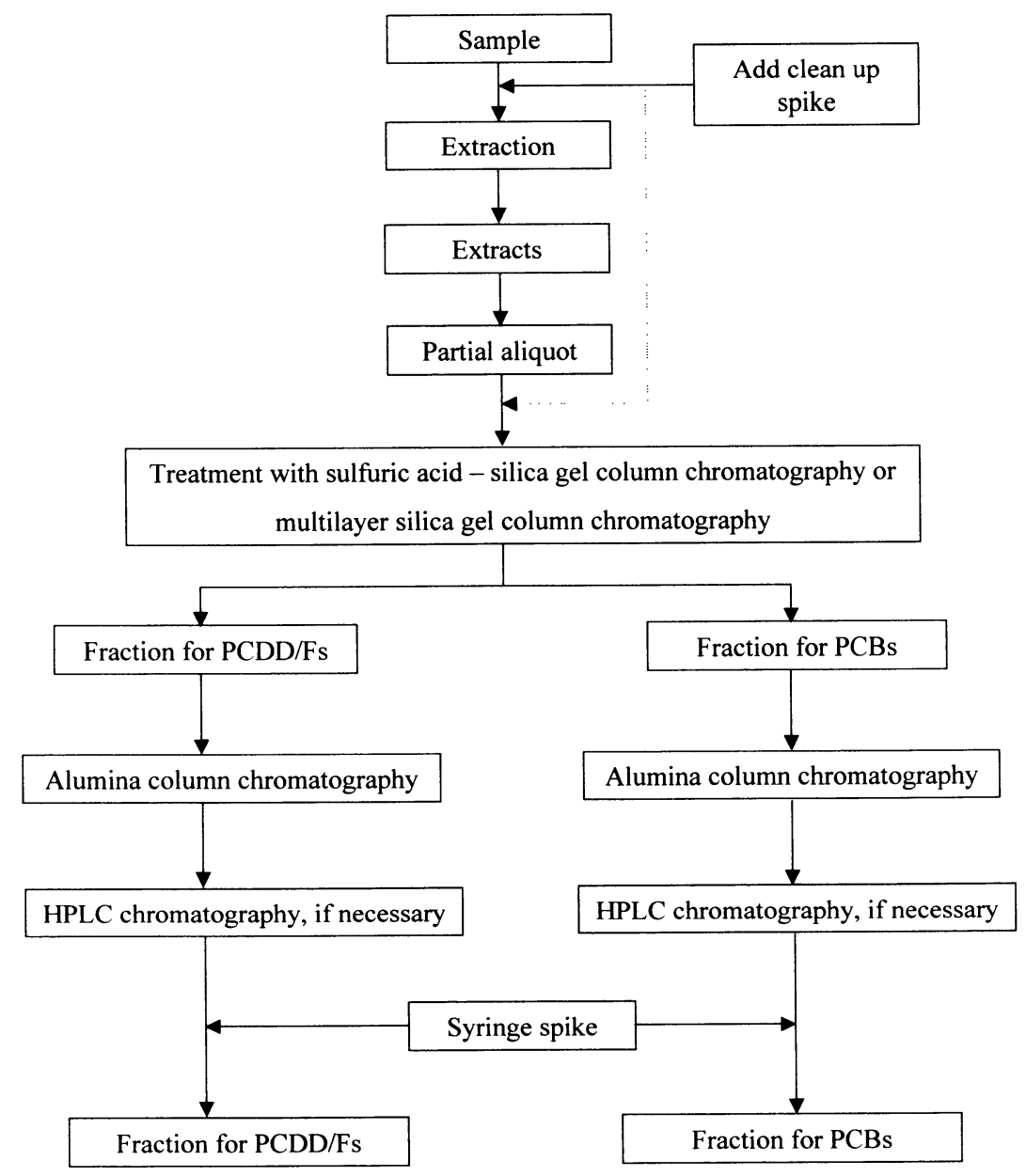

Fig. 3 Outline of analytical flow from clean up to measurement in JIS K 0311

in JIS K 0311 is the same as that in the KS method. For example; the resolution: $>10,000$ (10\% valley definition) at the appropriate $\mathrm{m} / \mathrm{z}$ and $>12,000$ with ${ }^{13} \mathrm{C}_{12-}$ $\mathrm{OCDF}$ as an internal standard.

Ionization mode (EI mode) and the lock mass method are also same in JIS K 0311 and the KS method. After injecting perfluorokerosene (PFK) as a standard substance for the mass calibration of the mass spectrometer, the mass pattern and resolution (more than $10,000,10 \%$ valley) should be tuned depending on the purpose of the determination. The other conditions of GC/MS measurement such as selected ion monitoring (SIM mode) and the mass numbers for monitoring ions of target dioxins, as well as their corresponding internal standards, are also nearly the same. For identifications, each congener should be identified by comparing the $\mathrm{GC}$ retention time and ion abundance ratio of two selected parent ions with those of their corresponding internal standards. The parent ion abundance ratio between the target congener and its corresponding internal standards should be within the designated limit. In both methods, all non-2, 3, 7, 8substituted dioxins are also quantitated using an average of the relative response factors from all of the labeled 2,3,7,8-substituted congeners with the same numbers of chlorine atoms.

For quantification, the isotope dilution method is used in both JIS K 0311 and the KS method, but JIS designated that the blank value should be subtracted. Furthermore, JIS K 0311 designated the details of the detection limits (DL) for each instrument, clean up method and measurement. 


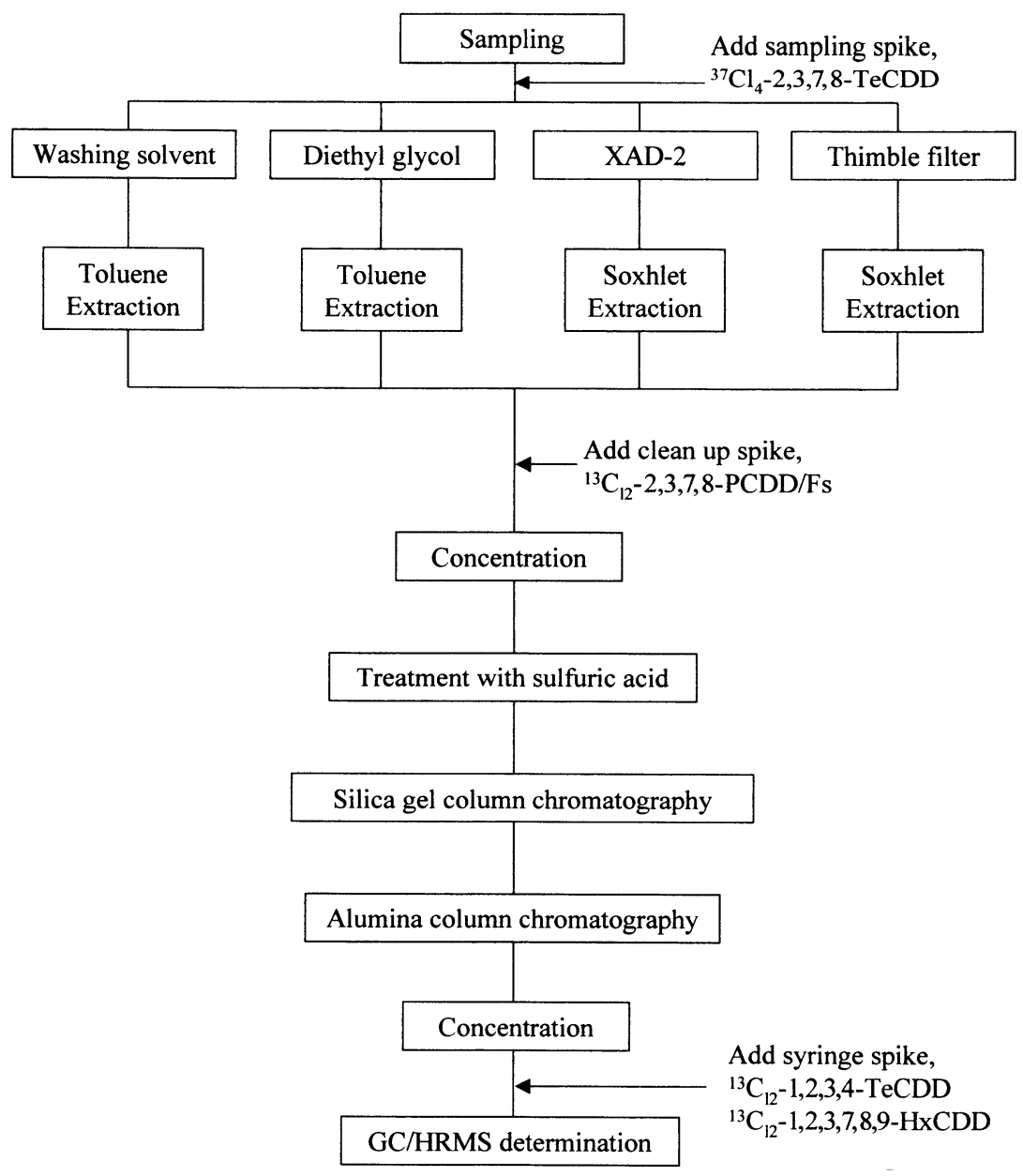

Fig. 4 Outline of analytical flow from clean up to measurement in KS method

For evaluation of toxic equivalents (TEQs), JIS K 0311 and the KS method use different toxicity equivalency factors (TEFs). JIS K 0311 adopts the TEF model $^{3)}$ suggested by the WHO in 1998, while the KS method adopts the TEF model ${ }^{4)}$ (I-TEF) established by NATO in 1989. Therefore, the direct comparison of TEQ values between Japan and Korea is not possible.

\section{DISCUSSION}

The KS method uses almost the same type of sampling trains and sampling methods as JIS K 0311. The sample volume in JIS K 0311 is calculated from the required detection limits, while in the KS method, an average $3 \mathrm{Nm}^{3}$ during $4 \mathrm{hr}$ is designated as the standard sample volume. Flexibility with respect to sample volume is likely to be suitable for various conditions in situ.

Sample clean up procedures designated in JIS $\mathrm{K}$ 0311 and the KS method are used world-wide and no significant differences were found between the two methods. JIS K 0311 recommends the optional use of multi-layered silica gel column chromatography instead of silica gel column chromatography, and if necessary, HPLC or activated carbon column chromatography after alumina column chromatography. Recently, Korean laboratories started using these clean up options ${ }^{5)}$. Therefore, the procedures should be added to the KS method in the near future.

The details of identification and quantification of dioxins using HRGC/HRMS with JIS K 0311 and the KS method are essentially the same except for some parts. For example, JIS K 0311 recommends the com- 
Table 3 Comparison of idenditication and quantification between JIS K 0311 and KS method

\begin{tabular}{|c|c|c|}
\hline Country & Japan & Korea \\
\hline Manual & JIS K 0311 & KS method \\
\hline \multicolumn{3}{|l|}{$\overline{\text { GC }}$} \\
\hline \multirow[t]{2}{*}{ Injector } & splitless or on-column type & splitless \\
\hline & $\max$ temp. $\quad 250 \sim 280^{\circ} \mathrm{C}$ & \\
\hline \multirow[t]{2}{*}{ Capillary Column } & $\begin{array}{l}\text { ID } 0.25 \sim 0.32 \mathrm{~mm} \text {, length } 25 \sim 60 \mathrm{~m} \text {. } \\
\text { fused silica capillary column }\end{array}$ & \\
\hline & $\begin{array}{l}\text { more than two types of capillary column } \\
\text { (polar and nonpolar types) }\end{array}$ & polar capillary column \\
\hline Carrier Gas & pure helium $(>99.9999 \%)$ & pure helium $(>99.9999 \%)$ \\
\hline Oven Temperature & temperature control range; $50 \sim 350^{\circ} \mathrm{C}$ & no designation \\
\hline \multirow[t]{8}{*}{ MS } & double focusing magnetic sector mass spectrometer & double focusing magnetic sector mass spectrometer \\
\hline & resolution $>10,000 \quad(12,000$ is necessary in case & resolution $>10,000 \quad(12,000$ is necessary in case \\
\hline & the use of ${ }^{13} \mathrm{C}_{12}$-OCDF as internal standard) & the use of ${ }^{13} \mathrm{C}_{12}$-OCDF as internal standard) \\
\hline & SIM-EI mode & SIM-EI mode \\
\hline & ion source chamber temp. $250 \sim 300^{\circ} \mathrm{C}$ & ion source chamber temp. $250 \sim 280^{\circ} \mathrm{C}$ \\
\hline & ionization current $0.5 \sim 1 \mathrm{~mA}$ & ionization current $0.3 \sim 0.5 \mathrm{~mA}$ \\
\hline & ionization voltage $30 \sim 70 \mathrm{~V}$ & ionization voltage $35 \sim 70 \mathrm{~V}$ \\
\hline & accelerating voltage $5 \sim 10 \mathrm{kV}$ & accelerating voltage $8 \sim 10 \mathrm{kV}$ \\
\hline \multirow[t]{3}{*}{ Mass } & ions monitored are more than two & ions monitored are more than two \\
\hline & lock mass method & lock mass method \\
\hline & grouping the channel is suitable & grouping the channel is suitable \\
\hline Calibration Curve & $\begin{array}{l}>3 \text { times injection of } 5 \text { steps of calibration standards, } \\
\text { RRF }\end{array}$ & $\begin{array}{l}>3 \text { times injection of } 5 \text { steps of calibration standards, } \\
R R F\end{array}$ \\
\hline Peak Detection & $\mathrm{S} / \mathrm{N}>3$, designation for signal and noise & $\mathrm{S} / \mathrm{N}>2.5$ \\
\hline \multirow[t]{2}{*}{ Identification } & relative isotope ratios within $15 \%$ & relative isotope ratios within $15 \%$ \\
\hline & the same retention time with internal standards & the same retention time with internal standards \\
\hline \multirow[t]{4}{*}{ Quantification } & isotope dilution method & isotope dilution method \\
\hline & subtract the blank value for concentration & no designation \\
\hline & $\begin{array}{l}\text { significant digits of the concentration should be rounded } 2 \\
\text { designation for detection limits }\end{array}$ & $\begin{array}{l}\text { significant digits of the concentration should be rounded } 2 \\
\text { no designation }\end{array}$ \\
\hline & $\begin{array}{l}\text { detection limits of sample gas, originated from the MDL, } \\
\text { should below the } 1 / 30 \text { of criteria }\end{array}$ & $\begin{array}{l}\text { quantification limits } 0.05 \mathrm{ng} / \mathrm{Nm}^{3} \\
\text { as } 2378 \text {-TCDD (ng-TEO } / \mathrm{Nm}^{3} \text { ) }\end{array}$ \\
\hline Calibration by $\mathrm{O}_{2}$ concentration & $\mathrm{C}=\left(21-\mathrm{O}_{\mathrm{n}}\right) /\left(21-\mathrm{O}_{\mathrm{s}}\right)^{*} \mathrm{C}_{\mathrm{s}}$ & $\mathrm{C}=(21-12 \%) /\left(21-\mathrm{O}_{\mathrm{s}}\right) * \mathrm{C}_{\mathrm{s}}$ \\
\hline TEQ & WHO-TEO (ng-TEQ $/ \mathrm{m}^{3}$ ) & $\mathrm{I}-\mathrm{TEO}$ (ng-TEO/Nm ${ }^{3}$ ) \\
\hline Others & $\begin{array}{l}\text { duplication of measurement } \\
\text { (if possible, within } 10 \% \text { frequency) }\end{array}$ & no designation \\
\hline
\end{tabular}

bined use of different polarity type capillary columns (polar and non-polar types), but the KS method designates that only the polar capillary column should be used. The relative sensitivity for highly chlorinated dioxins such as $\mathrm{HpCDD} / \mathrm{Fs}$, OCDD/F and for highly chlorinated Co-PCBs is commonly lower with a polar column compared to a non-polar and hydrophobic column. In addition, JIS $\mathrm{K} 0311$ suggests the identification method for the signal and noise values, but nothing is proposed in the KS method.

There are differences in the range of target compounds and the adoption of TEF between JIS K 0311 and the KS method. First, JIS K 0311 includes the coplanar PCBs as dioxin-like compounds. Therefore, CoPCB measurement is essential for the TEQ evaluation. However, only PCDDs and PCDFs are designated as dioxins in the $\mathrm{KS}$ method. There are timely discussions of the two points for Co-PCB measurement and adopting the new TEF-WHO ${ }_{1998}$ by the Korean committee for dioxins (personal communication). Therefore, modifi- cations will be added in the near future. In addition, the cross check for $\mathrm{QA} / \mathrm{QC}$ and improvements of analytical methods for dioxins in Japan and Korea will be instituted in the near future.

\section{CONCLUSIONS}

JIS K 0311 (Japan) and the KS method (Korea) were developed for congener-specific determination of $\mathrm{PCDD} / \mathrm{Fs}$ (and Co-PCBs) in the flue gas from MSWI using a combination of isotope dilution and high resolution capillary column gas chromatography (HRGC)/high resolution mass spectrometry (HRMS). In this study, these standard analytical methods were compared and discussed. There was no significant difference between the two methods with respect to sampling, preparations and identification/quantification. However, the coplanar PCBs and sort of TEF model adopted should be harmonized between Japan and Korea in order to compare the analytical data. We believe that this study will contribute to the standardization of an international 
method for dioxin analysis.

\section{ACKNOWLEDGMENT}

This study was supported by 'The Japan-Korea Cooperative Joint Research on Endocrine Disrupting Chemicals' of the Ministry of the Environment, Japan.

\section{REFERENCES}

1) JIS $\mathrm{K}$ 0311, Method for determination of tetrathrough octa-chlorodibenzo- $p$-dioxins, tetra- through octa-chlorodibenzofurans and coplanar polychlorobiphenyls in stationary source emissions, 1-61 (1999)

2) The Korean Standard Method for Air Pollution, 3, 614-637 (1999)

3) Van den Berg, M., Birnbaum, L., Bosveld, A.T.C., Brunstrom, B., Cook, P., Feeley, M., Giesy, J.P.,
Handberg, A., Hasegawa, R., Kennedy, S.W., Kubiak, T., Larsen, J.C., Rolf van Leewen, F.X., Djien Liem, A.K., Nolt, S., Peterson, R.E., Poellinger, L., Safe, S., Schrenk, D., Tillit, D., Tysklind, M., Younes, M., Waern, F. and Zacharewski, T.: Toxic Equivalency Factors (TEFs) for PCBs, PCDDs, PCDFs for Humans and Wildlife. Environ. Health. Perspect., 106, 775-792 (1998)

4) NATO/CCMS: International toxic equivalency factors (I-TEF) method of risk assessments for complex mixtures of dioxins and related compounds. Bussels, Report no. 176 (1988)

5) Ok, G., Suk, H.J., Ji, S.H., Moon, H.B. and Lee, H.H.: Behavior of PCDDs/DFs in fly ash from municipal waste incineration plant. Korean Society of Environmental. Analysis, 1, 33-40 (1998) 